\title{
Factors influencing successful implementation of the basic antenatal care approach in primary health care facilities in eThekwini district, KwaZulu-Natal
}

\begin{tabular}{|c|c|}
\hline \multicolumn{2}{|c|}{$\begin{array}{l}\text { Authors: } \\
\text { Thembelihle S.P. Ngxongo }{ }^{1} \\
\text { Maureen N. Sibiya }^{1}\end{array}$} \\
\hline \multicolumn{2}{|c|}{$\begin{array}{l}\text { Affiliations: } \\
{ }^{1} \text { Department of Nursing, } \\
\text { Durban University of } \\
\text { Technology, South Africa }\end{array}$} \\
\hline \multicolumn{2}{|c|}{$\begin{array}{l}\text { Correspondence to: } \\
\text { Thembelihle Ngxongo }\end{array}$} \\
\hline \multicolumn{2}{|c|}{$\begin{array}{l}\text { Email: } \\
\text { thembelihlen@dutac.za }\end{array}$} \\
\hline \multicolumn{2}{|c|}{$\begin{array}{l}\text { Postal address: } \\
\text { PO Box 1334, Durban 4000, } \\
\text { South Africa }\end{array}$} \\
\hline \multicolumn{2}{|c|}{$\begin{array}{l}\text { Dates: } \\
\text { Received: } 27 \text { Jan. } 2012 \\
\text { Accepted: } 28 \text { Jan. } 2013 \\
\text { Published: } 07 \text { May } 2013\end{array}$} \\
\hline \multicolumn{2}{|c|}{$\begin{array}{l}\text { How to cite this article: } \\
\text { Ngxongo, T.S.P. \& Sibiya, } \\
\text { M.N., 2013, 'Factors } \\
\text { influencing successful } \\
\text { implementation of the basic } \\
\text { antenatal care approach } \\
\text { in primary health care } \\
\text { facilities in eThekwini district, } \\
\text { KwaZulu-Natal', Curationis } \\
\text { 36(1), Art. \#92, } 7 \text { pages. } \\
\text { http://dx.doi.org/10.4102/ } \\
\text { curationis.v36i1.92 }\end{array}$} \\
\hline \multicolumn{2}{|c|}{$\begin{array}{l}\text { Copyright: } \\
\text { C 2013. The Authors. } \\
\text { Licensee: AOSIS } \\
\text { OpenJournals. This wC } \\
\text { is licensed under the } \\
\text { Creative Commons } \\
\text { Attribution License. }\end{array}$} \\
\hline \multicolumn{2}{|l|}{ Read online: } \\
\hline 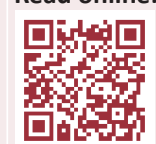 & $\begin{array}{l}\text { Scan this QR } \\
\text { code with your } \\
\text { smart phone or } \\
\text { mobile device } \\
\text { to read online. }\end{array}$ \\
\hline
\end{tabular}

Background: In a move to alleviate the burden of consistently high maternal and perinatal mortality rates, the South African National Department of Health (DoH) introduced Basic Antenatal Care (BANC) in all Primary Health Care facilities that were providing antenatal care services. However, not all facilities in the eThekwini district have successfully implemented the approach. The aim of the study was to identify the factors that influence successful implementation of the BANC approach.

Objectives: The objectives were to identify facilities that had successfully implemented the BANC approach and the factors that influenced successful implementation of the BANC approach, in order to make recommendations on these factors.

Method: A descriptive quantitative design was used. Firstly, primary health care facilities that were successful in implementing the BANC approach were identified through a retrospective record auditing. A total of 27 facilities were identified, of which 18 facilities were included in the study. This was followed by data collection from 59 midwives in order to identify the factors that influenced successful implementation of the BANC approach. The data was analysed using version 19 of the Statistical Package for the Social Sciences.

Results: The positive factors that influenced successful implementation of the BANC approach included: the availability and accessibility of BANC services, policies, guidelines and protocol; various means of communication; a comprehensive package of and the integration of primary health care services; training and in-service education; human and material resources; the support and supervision offered to the midwives by the primary health care supervisors; supervisors' understanding of the approach and the levels of experience of midwives involved in implementation of the BANC approach.

Conclusion: The success that the facilities had achieved in implementing BANC approach was attributed to these positive factors.

\section{Introduction}

In its endeavour to achieve Millennium Development Goals (MDG) four and five of reducing perinatal deaths and improve maternal health by 2015, the South African National Department of Health $(\mathrm{DoH})$, included maternal health care as one of the priority programmes for the country (DoH 2002). The increase of maternal death reporting, by 20\% during 2005-2007 trienniums, when comparing it to the 2002-2004 trienniums made maternal and perinatal death rates to remain the major challenge of health care in South Africa (DoH 2005). South Africa has more stillbirths than neonatal deaths, which is a reflection of poor quality Antenatal Care (ANC) (DoH 2005). Many interventions for preventing stillbirths can be delivered through and alongside existing Maternal, Newborn, Child and Women's Health (MNCWH) programmes (Zulfiqar et al. 2010). The provision of effective ANC is regarded as the cornerstone for maternal and perinatal care and a good tool for reducing maternal and perinatal mortality rates (DoH 2008a).

ANC programmes in developing countries have been modelled on the approaches that are used in developed countries. In these approaches more resources, which are usually scarce in the developing countries, are devoted unnecessarily to women with low risks. Instead the World Health Organisation (WHO) designed and tested a package of ANC that includes only procedures and tests that serve an immediate purpose and have a proven health benefit (Maternal and Neonatal Health programme $[\mathrm{MNH}] 2004)$. This approach reduces the number of ANC visits to four and it has not been found to pose a risk to the health of mother or the baby (Villar et al. 2007). This approach has been adopted by various countries, some of which have modified it to suit the circumstances of the country for example Argentina, Cuba, Saudi Arabia, Thailand, 
Zimbabwe and South Africa. In South Africa the approach is called 'BANC' (Basic Antenatal Care) and is included in the ten year strategic plan for 2006-2015, as the key implementation strategy for MNCWH in an attempt to reduce maternal and perinatal death rates (DoH 2010). The BANC approach makes the analysis and grouping of women according to their risk factors much easier and has been simplified to the bare minimum so that ANC service can be provided by every midwife (Pattinson 2005). However, the approach could be difficult to implement because of scarce resources and high staff turnover at certain health facilities (WHO 2002).

The National DoH introduced the BANC approach in 2007 and advised that all the health facilities that are providing ANC services should adopt this approach by the end of 2008 (DoH 2008b). The National DoH, provided training on the BANC approach to all the provinces. Also various documents such as the handbook, guidelines and facility manager's guides were made available. Implementation in eThekwini district commenced as a pilot project in few facilities in the North Sub district in 2007 and was rolled out to all the three sub-districts in 2008. However, the researcher has observed that not all eThekwini municipal Primary Health Care (PHC) facilities have been successful in implementing the BANC approach.

\section{Problem statement}

EThekwini Municipality Health Unit has not achieved the target that was set by the National DoH for all the PHC facilities to implement the BANC approach by the end of 2008. Some facilities have failed to implement, whilst the others attempted the implementation but failed to sustain it.

\section{Aims and objectives of the study}

The aim of the study was to identify the factors that influence successful implementation of the BANC approach. The objectives were to identify facilities that had successfully implemented the BANC approach and the factors that influenced successful implementation of the BANC approach.

\section{Significance of the study}

Identification of the factors that influence successful implementation of the BANC approach can assist to strengthen and sustain the use of this approach across the country. Access to research articles on the BANC approach would benefit countries who either wish to adopt the approach or to strengthen their ANC approaches.

\section{Literature review and trends regarding approach to ANC}

ANC is regarded as a component of routine MNCWH services, and is aimed at targeting the population of pregnant women in order to screen and detect early signs of risk factors for diseases. This screening is then followed by timely interventions, with the aspiration of reducing maternal and perinatal mortality and morbidity (Pen-Kekana, Parkhurst \& McPake 2006). A number of studies have highlighted that quality ANC is the key to reducing maternal and child mortality rates (DoH 2007; Mathole, Lindmark \& Ahlberg 2005; Villar et al. 2007; WHO 2002;). Non-attendance of ANC increased the risk of maternal deaths by approximately four times, compared with the general pregnant population (DoH 2005). Zulfiqar et al., (2010) recommends that the promotion of quality ANC and efficient referral system should be promoted as a platform for improving coverage of evidence-based interventions towards saving babies and reducing the stillbirth rate. The quality of health care that a pregnant woman receives during ANC has an impact on the health of the woman and the outcome of the pregnancy (Snyman 2007). This author further states that there are many factors in PHC which could impact on and influence the quality of ANC. These include whether a comprehensive approach, rather than fragmented approach, is being used, along with the qualifications of the nurses and whether they were trained as midwives, since according to the DoH (2001) every nurse is expected to provide all services. The one stop shop or supermarket approach ensures that comprehensive and holistic health care is provided for the patient and this can be achieved if services are integrated and are available every day of the week (Sibiya \& Gwele 2009). It is important that ANC services are provided at every point where women present and that health services are integrated because this will facilitate early diagnosis of pregnancy and immediate provision of the first ANC service (Pattinson 2005).

Oakland (2008) states that people's attitudes and behaviours could be influenced by communication. According to Steenkamp \& Schoor (2008) internal communication plays an important role in the creation of a happy and productive workforce. According to Oakland (2008) failure to communicate effectively could create unnecessary problems which could result in confusion, loss of interest and eventually, in declining quality through apparent lack of guidance and stimulus.

The implementation of BANC is seen as a positive measure to improve the quality of ANC in PHC facilities and could potentially, have a positive impact on the outcome of pregnancy (Snyman 2007). If a pregnant woman is brought into the system early, her health problem could be detected and managed or controlled early and treatment then has a greater chance of success (Pattinson 2005).

The BANC approach demands that facilities undergo a process of change. It is essential for health services to implement system change in response to risk areas identified by reviewing adverse events in order to achieve continuous quality improvement and the delivery of safe quality care (Victoria Quality Council 2006). Strategies that may improve the likelihood of success of the change process are; engaging others, communication, motivation, sharing results, evaluation, and using a pilot. Zegart (2011) states that implementing change and improving organisational performance is never easy because several challenges may confront the organisation and hinder progress. Zegart (2011) stresses the importance of perfect rational decision making 
so that all relevant options are sorted, and the best decisions are then made. Successful implementation of change may be hindered by scarce resources and staff turnover (Victoria Quality Council 2006).

The journey to mastery in any field moves from novice to experts and for the novice, the providers need rules and close monitoring as opposed to the expert where a person has a vision of what is possible and uses analytical approaches and needs concepts and vision (McClure 2005). According to Murray and Haulb (2003) humans are able to improve task performance as a result of repeated experience with a particular task.

\section{Research method design Design}

A non-experimental descriptive quantitative design was used to identify the factors that influenced successful implementation of the BANC approach.

\section{Sampling and sampling technique}

A four phased sampling technique was used. In phase one all 59 (100\%) managers of the 59 (100\%) municipal PHC facilities were sampled to be included in the first phase of the study. The aim was to conduct structured telephonic interviews with the managers in order to identify the facilities that were implementing the BANC approach. Thirty nine (66\%) PHC facilities were using the BANC approach. Data was collected from these PHC facilities in order to identify the facilities that were successfully implementing the BANC approach, which was the first objective of the study. The study results revealed that there were 27 (46\%) municipal PHC facilities that were successfully implementing the BANC approach.

In phase two the PHC facilities that were implementing the BANC approach were first clustered according to the three sub-districts in order to ensure that all three eThekwini Municipality sub-districts were each equally represented in the sample. A total of $18(67 \%)$ PHC facilities were randomly selected from the 27 facilities that were identified to successfully implement the BANC approach.

Sampling done in phase three was to select the records to be used during a retrospective record review. The records from 2008 to 2010 were selected using a purposive random sampling method. In each facility 20 BANC checklists for the clients that previously attended ANC and had given birth were selected. A total of 360 records were selected and reviewed.

Phase four involved convenient sampling of all midwives who agreed to take part in the study. Each Municipal PHC facility had between 2 and 6 midwives in its staff complement. All midwives, who were working in the sampled facilities and who agreed to take part in the study, were included. A total of 59 midwives were included in the sample.

\section{Data collection}

Data collection was done in two phases. The first phase involved a retrospective auditing of all eThekwini Municipality PHC facilities in order to identify those that were successfully implementing the BANC approach. First an interview guide with structured questions was used to conduct structured telephonic interviews with the managers of the PHC facilities. An interview is a data collection method in which an interviewer asks questions, either face to face or by telephone (Polit \& Beck 2008). This was followed by a retrospective review of the past records using a checklist adapted from the BANC National DoH checklist for ANC record review. Polit and Beck (2008) describe a checklist as a list of several questions with the same response format.

In the second phase, a self-administered questionnaire was used to collect data from the midwives in order to identify the factors that influenced the successful implementation of the BANC approach. A questionnaire is a printed self-report form designated to elicit information that can be obtained from a subject's written response (Burns \& Grove 2009).

\section{Pilot study}

A pilot study was conducted to refine the methodology or the data collection process. A total of six midwives from the three clinics that had successfully implemented the BANC approach, were used for the pilot study. The results of the pilot study revealed that the participants had a clear understanding of the questions. No changes were made on the questionnaire. The checklist was not piloted because it was adapted from the tool that had already been tested and verified.

\section{Data analysis}

The data from the checklists and the questionnaires were captured and subsequently analysed using version 19 of the Statistical Package for the Social Sciences (SPSS). Descriptive statistics, such as frequencies percentage and $\mathrm{P}$ values, were used to present data.

\section{Context of the study}

The study was conducted in the fixed PHC facilities of eThekwini Municipality. eThekwini District is the largest of the eleven districts in KwaZulu-Natal (KZN) (DoH 2010). The provision of PHC services is shared between the KZN Provincial Administration (KZNPA) and eThekwini Municipality. There are 100 PHC facilities in eThekwini district, of which 59\% (59 facilities) belong to the Municipality and the other $41 \%$ (41 facilities) fall under the KZNPA (DoH 2010).

\section{Results \\ Identification of facilities that had successfully implemented the BANC approach}

Out of 59 (100\%) eThekwini Municipality PHC facilities, 57 (97\%) were providing ANC services, 39(68\%) were using 
the BANC approach, and $27(47 \%)$ were using the BANC checklists and identified as successfully implementing the BANC approach.

\section{Record review}

Out of 360 records reviewed the 'Yes' scores for the majority of the elements assessed were between 192 and 360 (53.3\% $-100 \%$ ). These findings were an indication that the facilities that were included in the study were compliant with the provision of BANC guidelines. However, there were also a significant number of elements for which the 'Yes' scores were $47-172(13.1 \%-47.8 \%)$. These are the areas which the facilities still needed to address.

Table $1 \mathrm{a}$ and Table $1 \mathrm{~b}$ below represent a summary of the study findings for review of past records. The areas that are not shaded indicate responses below $50 \%$ and the shaded areas indicate responses greater or equal to $50 \%$

\section{Midwives' questionnaire Provision of the BANC services}

Table 2 below represents the summary of responses from the midwives. The findings were converted to responses per facility because due to nature of the questions and information required, responses by midwives from the same facilities were similar.

\section{Ethical consideration}

The study was only commenced after the study design, procedures and questionnaires had been approved by Durban University of Technology Faculty Research Committee and eThekwini Municipality Health Research Unit. The right to protection from exploitation and freedom of speech was ensured by using a trained research assistant to administer and collect the questionnaires. This ensured that the midwives were not intimidated by the presence of the researcher who was coordinating the $\mathrm{MNCWH}$ programme for eThekwini Municipality. All the participants were required to sign an informed consent to ensure that they willingly and knowingly participated in the study. The data collection tools were identified by numbers to eliminate any link between the participants' identity and the information gathered in order to maintain confidentiality.

\section{Reliability and validity}

Reliability was ensured by conducting a pilot study on six midwives from three clinics that had successfully implemented the BANC approach. A checklist that had

TABLE1a: Results of record review.

\begin{tabular}{|c|c|c|c|c|}
\hline Checklists classifying (First) visit & $\%$ & $f$ & $p$-value & Significantly more than expected respondent \\
\hline The use of checklists classifying (first) visit & 100 & 360 & $<.0005$ & yes \\
\hline Doing the First visit on or before the woman was 20 weeks pregnant & 75.8 & 273 & $<.0005$ & yes \\
\hline Filling of checklists classifying (first) visit & 69.2 & 249 & $<.0005$ & yes \\
\hline Indication on the checklist whether the woman is eligible for BANC (with Yes or No) & 68.3 & 246 & $<.0005$ & yes \\
\hline Sticker to indicate whether client is eligible for BANC & 38.98 & 140 & $<.0005$ & no \\
\hline
\end{tabular}

f, Frequency.

TABLE1b: Results of record review.

\begin{tabular}{|c|c|c|c|c|}
\hline Clinic checklist-classifying (follow up) & $\%$ & $f$ & $p$-value & Significantly more than expected respondent \\
\hline \multicolumn{5}{|l|}{ 1. Use of checklist } \\
\hline Counter signing of the checklist at 38 weeks & 26.98 & 97 & $<.0005$ & no \\
\hline Filling of Clinic checklist-classifying (follow up) & 73.38 & 264 & $<.0005$ & yes \\
\hline Checklist filed according to return dates for the clients & 70.08 & 252 & $<.0005$ & yes \\
\hline \multicolumn{5}{|l|}{ 2. Scheduling of ANC visits } \\
\hline Scheduled visits recorded on the checklist & 40.68 & 146 & $<.0005$ & no \\
\hline 20 weeks follow up visit & 60.68 & 218 & $<.0005$ & no \\
\hline 26 weeks follow up visit & 53.38 & 192 & 0.206 & \\
\hline 32 weeks follows up visit & 47.88 & 172 & 0.399 & \\
\hline 38 weeks follow up visit & 34.28 & 123 & $<.0005$ & no \\
\hline Record of ANC visits after 38 weeks gestation & 29.28 & 105 & $<.0005$ & no \\
\hline Appointment to attend the hospital if client had not given birth by 40 weeks & 23.38 & 84 & $<.0005$ & no \\
\hline Record of Additional ANC visits & 60.88 & 219 & $<.0005$ & yes \\
\hline \multicolumn{5}{|l|}{ 3. Routine investigations, procedures and prophylaxis } \\
\hline $\mathrm{Hb}$ check at 32 weeks & 28.98 & 104 & $<.0005$ & no \\
\hline $\mathrm{Hb}$ check at 38 weeks & 13.18 & 47 & $<.0005$ & no \\
\hline RPR test during first visit & 84.78 & 305 & $<.0005$ & yes \\
\hline RPR test repeated at 38 weeks if the test was negative at first booking & 25.38 & 91 & $<.0005$ & no \\
\hline Client tested for HIV & 89.28 & 321 & $<.0005$ & yes \\
\hline WHO staging done for HIV positive client & 22.58 & 81 & $<.0005$ & no \\
\hline Client issued with calcium supplements & 70.08 & 252 & $<.0005$ & yes \\
\hline Discussion of delivery plan with client & 57.28 & 206 & 0.006 & no \\
\hline
\end{tabular}

ANC, Antenatal Care; WHO, World Health Organization; RPR, Rapid plasma reagin; Hb, Haemoglobin.

$f$, Frequency. 
TABLE 2: Responses from the midwives.

\begin{tabular}{llll}
\hline Element & Assessment & $\mathbf{\%}$ & $\boldsymbol{n}$ \\
\hline Frequency of ANC clinic & Every week day & 94.4 & 17 \\
Number of midwives per facility & $\leq$ 2midwives & 100.0 & 18 \\
Number of BANC trained midwives & $\leq 1$ midwives & 100.0 & 18 \\
Participants trained in BANC & & 45.8 & 27 \\
Duration of BANC implementation & $\leq 2$ years & 77.8 & 14 \\
Frequency of in-service training on BANC & $\geq$ once a month & 54.4 & 10 \\
Manager trained in BANC & yes & 72.2 & 14 \\
Manager doing ANC supervisory visits & yes & 72.2 & 14 \\
Support received & yes & 83.1 & 15 \\
Policies and Guidelines & All available & 94.4 & 17 \\
Means of communication & available & 100.0 & 18 \\
Nurse to patient ratio & $\geq 1: 10$ & 54.4 & 10 \\
Average number of clients (first visit) & $\leq 10$ & 72.2 & 13 \\
& 10 & 27.8 & 5 \\
Average number of clients (repeat visits) & $\leq 10$ & 66.7 & 12 \\
& $\geq 1: 10$ & 33.3 & 6 \\
\hline
\end{tabular}

ANC, Antenatal Care; BANC, Basic Antenatal Care.

$n$, Given as a number.

already been tested and verified was used for record review. Colleagues in the midwifery field were used to check the clarity of the questions in the interview guide. Data was collected from the clinics that had successfully implemented the BANC approach as well as from participants who were directly involved in implementing the BANC approach to ensure reliability and content validity and that the findings were unbiased and well-grounded.

\section{Discussion}

The results of the record review, which revealed that only $27(47 \%)$ facilities were successfully implementing BANC, confirmed that not all eThekwini Municipality PHC facilities were successfully implementing the BANC approach, which was what prompted the need to conduct the study. The study results for most of the elements assessed during the record review confirmed that the facilities that were included in the study were successfully implementing the BANC approach. BANC services were available every day of the week in 17 (94\%) facilities that were included in the study, except for one (5.6\%) facility in which the ANC services were provided twice a week. When BANC services are available every day of the week, pregnant women are able to access the ANC service as soon as pregnancy is diagnosed, or the very same day on which the pregnant women presents to the health facility (Pattinson 2005). This prevents clients from, either being turned away or asked to come back another day, a practice which creates a low opportunity for early ANC attendance. Policies and guidelines were available in 17 (94.4\%) facilities. Since BANC is a new concept, it is important that relevant BANC policies and guidelines are available in the facilities to assist staff during the implementation of the approach. Dave (2004) suggests that people start as novices, and novices need the guidance of rules, rapid feedback and a safe environment. Good and varying means of communication that existed in $18(100 \%)$ of the facilities contributed to the success that the facilities had in implementing BANC. Oakland (2008), suggests that it is essential to provide relevant information, convey good practices and generate interest, ideas and awareness through excellent communication processes. A comprehensive package of services was offered in $18(100 \%)$ of the facilities, thus ensuring access to most services including ANC services. The finding concurs that the strategies to integrate primary health care aim to bring together inputs, organisation, management and delivery of particular service functions to make them both more efficient and accessible to the service user that will dictate new skills and knowledge (Myers 2005). This author suggests that the development and use of integrated healthcare systems is an absolute necessity in the support of the delivery of low cost, high-quality care. However, this requires cooperation and coordination not previously experienced in the sector. The benefits resulting from an integrated healthcare environment could greatly assist the various caregivers in making correct assessments and administering the proper treatments, as well as facilitating the optimisation of operations across the enterprise. Integration of PHC services is an important strategy towards the achievement of the national goals of transformation of health services, and the attainment of a comprehensive and seamless public health system (Sibiya \& Gwele 2009).

Midwives from $15(83.1 \%)$ of the facilities stated that they were getting support from their managers. The managers from $14(72.2 \%)$ of the facilities were doing supervisory visits. The findings of a study conducted in rural Zimbabwe on midwives' dilemmas and paradoxes in providing and changing ANC revealed that caregivers noted that too many programmes were included in the package of services (Mathole et al. 2005). The caregivers reported that the large number of programmes that were implemented simultaneously was interfering with their performance. These findings emphasise the importance of both integration of services and monitoring of the workload. Participants indicated that in-service education and workshops were used as the means of communication in all 18 (100\%) of the facilities. In service education was conducted at least once a month in ten $(54.4 \%)$ of the facilities. It is critical for the organisation to provide individuals with avenues of service and opportunities for personal development that match their skills and interests and offer training, mentoring and professional development support (Meadows 2006). The midwives (100\%) each had more than two years as practicing midwives. The experience of the midwives who were working in ANC had an impact on the success of the BANC implementation. High quality experience turns human beings from novices to someone approaching experts (Dave 2004). Fourteen (72.2\%) supervisors were trained in BANC and were providing good supportive supervision to the midwives and also conducted communication meetings, compared to those that were not trained in BANC. A good leader would be able to identify the organisational goals or specific targets and should be able to impart these goals to his team members and commit them to work hard and intelligently to achieve organisational goals (True Leadership 2009). Supervision is about building trusting relationships with employees as mutual trust allows them to apply their thoughts and efforts to each situation. This strong working 
relationship then builds the commitment necessary to get the work done (Greenfield 2006). Greenfield also stated that the role of the organisational leader should be that of a facilitator who; encourages organisational development, encourages staff to assume leadership roles, and pushes the organisation to change where it needs to. The BANC trained supervisors had a better understanding of the approach. Kouzes and Posner (2002), as well as Catenacci (2010), state that people want to follow someone who is competent. Catenacci (2010) states that people want to follow someone who is competent.

The nurse patient ratio in the facilities was less than 1:10 in ten $(54.4 \%)$, which is in line with two to three midwives for every 100 bookings $=1: 30$ as a recommended staffing norm in the saving babies' report (DoH 2005). Successful implementation of BANC was also influenced by the staffing norm that prevailed in the facilities. Pattinson (2005) states that the provision of sufficient skilled staff was important for accurate and successful provision of ANC. Constant availability of material resources is also noted as an important factor that influenced the successful implementation of BANC. During the sampling phase two of the facilities indicated that they had stopped providing BANC because they had run out of BANC checklists. This indicates the need for the organisation to ensure that human and material resources are available and sustained.

\section{Limitations of the study}

The study only investigated the factors that influenced successfully implemented BANC approach and did not investigate the factors that hindered implementation of the approach.

\section{Recommendations}

- Relevant policies and protocols on BANC should be made available at all institutions providing ANC.

- Supportive supervision should be strengthened to ensure that midwives gain adequate support and guidance.

- Human and material resources should be reviewed for adequacy when new programmes are introduced, whilst maintaining adequate and constant supply at all time.

- Open communication should be available at all levels of care and in all directions to ensure that relevant new information is cascaded accordingly and timeously.

- Services should be fully integrated to ensure accessibility and availability of BANC services.

- BANC services should be available every day of the week and at every health service where women present.

- Effective training and skills development, including a commitment to on-going learning and development, is needed to ensure successful implementation of the BANC approach.

- The department should work towards getting every midwife trained in BANC. Where circumstances do not allow the training of all midwives, each facility should strive to have more than one midwife trained in BANC so that the trained midwives are able to complement each other.
- BANC training should be incorporated into the basic midwifery training so that every trained midwife is able to use the BANC approach to ANC.

- Supervisors should also be included in training so that they have a full understanding of the approach.

- Further research should be undertaken in order to identify the factors that are preventing other facilities from implementing the BANC approach.

\section{Conclusion}

The overall findings of the study were that the positive factors that prevailed in the facilities contributed to the successful implementation of the BANC programme. The negative factors identified revealed that, although the facilities were successfully implementing the BANC programme, there was still room for improvement in order to achieve full success.

\section{Acknowledgements}

The authors would like to thank and acknowledge the following people for their contributions to the study. Mr. ANB. Ngxongo, who was the study assistant during data collection, Mrs. G. Henrys for assisting with data analysis, and Mrs. L. Robinson for editing all the work.

\section{Competing interests}

The authors declare that they have no financial or personal relationships which may have inappropriately influenced them in writing this article.

\section{Authors' contributions}

T.S.P.N. (Durban University of Technology) Primary investigator. She collected and analysed data. M.N.S. (Durban University of Technology) Secondary investigator She provided guidance and support.

\section{References}

Burns, N. \& Grove, S.K., 2009 The Practice of Nursing Research, 6th edn., Elsevier, Texas.

Catenacci, D., 2010, Inadequate or no Maintenance and Supervision, viewed 13 June 2010, from http://www.zimbio.com/DanielCatenacci

Dave, T., 2004, Pragmatic Programmer: End of the Knowledge Worker, viewed 13 June 2010, from http://pragdave.pragprog.com/pragdave/2004/04/ endoftheknowhtml

Department of Health (DoH), 2001, The Primary Health Care Package for South Africa - A set of Norms and Standards, Government Printer, Pretoria.

Department of Health (DoH), 2002, 2nd edn., Guidelines for Maternity Care in South Africa, A Manual for Clinics, Community Health Care Centres and District Hospitals, Government Printer, Pretoria.

Department of Health (DoH), 2005, Saving Mothers 2002-2004: Fourth Report on Confidential Enquiries into Maternal Deaths in South Africa; Expanded Executive Summary, Government Printer, Pretoria.

Department of Health: Republic of South Africa (DoH), 2007, Saving Babies V: Fifth Perinatal Care Survey of South Africa for 2003-2005, The MRC Unit for Maternal and Infant Care Strategies, PPIP Users, and the National Department of Health, Pretoria.

Department of Health (DoH), 2008a, Saving Mothers 2005-2007: Fourth Report on Confidential Enquiries into Maternal Deaths in South Africa; Expanded Executive Summary, Government Printer, Pretoria.

Department of Health (DoH), 2008b, Strategic Plan for Maternal, Neonatal, Child and Women's Health (MNCWH) and Nutrition in South Africa for 2009-2014, Government Printer, Pretoria.

Department of Health (DoH), 2010, KwaZulu-Natal Department of Health Strategic Plan 2010-2014, Government Printer, Pretoria. 
Greenfield, D.H., 2006, 'Midwifery needs in a Maternity Ward', Proceedings of the 25th Conference on Priorities in Southern Africa, Champagne Sports Resort.

Ilboudo, T.P., Chou, Y.-J. \& Huang, N., 2011, 'Compliance with referral for curative care in rural Burkina Faso', Health Policy Plan, Oxford Journals, viewed 13 June 2010, from www.heapol.oxfordjournals.org/content/early/2011/05/25/heapol. czr041

Kouzes, J. \& Posner, B., 2002, The Leadership Challenge, viewed 06 July 2011, from http://www.changingminds.org/books/book/kouzes_posner.htm

Maternal and Neonatal Health Programme, 2004, Focused Antenatal Care: Planning and Providing Care During Pregnancy, viewed 10 February 2010, from http:// www.mnh.jhpiego.org

Mathole, T., Lindmark, G. \& Ahlberg, G., 2005, Health Policy and Planning, Dilemmas and Paradoxes in Providing and Changing Antenatal Care 20(6), viewed 09 February 2010, from http://www.heapol.oxfordjournals.org/cgi/content/ full/20/6/385

McClure C., 2005, Dreyfus Model of Skill Acquisition, viewed 15 June 2011, from http://www.docstoc.com/search/skills-acquisition

Meadows, L., 2006. The Importance of Training, viewed 05 September 2011, from http://www.evancarmichael.com/The-Importance-of-Training.html

Murray, K.B. \& Haulb, G., 2003, A human Capital Perspective of Skill Acquisition and Interface Loyalty, Communications of the ACM, viewed 08 July 2011 from http://www.vincentvanrooijen.com/container\%5CRequirements\%2 Management\%5CUser\%20Interaction\%5Cb

Myers, J.E., 2005, Data Modelling for Healthcare Systems Integration: Use of the MetaModel, viewed 08 July 2011, from http://www.metadata.com/whitepapers/ myers1.pdf

Oakland, J.S., 2008, Total Quality Management text with cases, 3rd edn., Burlington: Elsevier

Pattinson, R.C., 2005, Basic Ante Natal Care Handbook, University of Pretoria, Pretoria.
Pen-Kekana, L., Parkhurst, J. \& McPake, B., 2006, Making Progress in reducing maternal mortality and morbidity- need to conceptualize approach to health systems Health mystem Development Programme, viewed 05 September 2011, from http://www. dfid.gov.uk/r4d/PDF/Outputs//maternalmortalitywebversion.pdf

Polit, D.F. \& Beck, C.T, 2008, 8th edn., Nursing Research, Generating and Assessing Evidence for Nursing Practice, Wolters Kluwer, Lippincott Williams and Wilkins, Philadelphia.

Sibiya, M.N. \& Gwele, N.S., 2009, A model for the integration of primary health care services in the province of KwaZulu-Natal, South Africa: Durban University of Technology, viewed 24 September 2011, from http://www.ijic.org/index.php/ijic/ article/view/635

Snyman, J.S., 2007, Effectiveness of the Basic Antenatal Care Package in Primary Heath Care Clinics. Thesis submitted in fulfilment of the requirements for the degree Magister Curationis in the Faculty of Health Sciences at the Nelson Mandela Metropolitan University, South Africa, viewed 02 August 2011, from http://www. nmmu.ac.za/documents/theses/Complete\%20Thesis.pdf

Steenkamp, R. \& Van Schoor, A., 2008, The Quest for Quality of Worklife: A TQM Approach, Juta Academic, Lansdowne.

True Leadership, 2009, Characteristics of Good Leadership - Review of Theories, Practices including Transactional Transformational Qualities. viewed 24 May 2011, from http://true-leadership.info/characteristics-of-good-leadership.html

Victorian Quality Council, 2006, Successfully Implementing Change, viewed 09 February 2010, from http://www.health.vic.gov.au/qualitycouncil/successfully_ implementing_change.pdf

Villar, J, Carroli, G., Khan-Neelofur, D., Piaggo, G. \& Gulmezoglu, M., 2007, Patterns of Routine Antenatal Care for Low-Risk Pregnancies, Database of systematic Review, viewed 09 February 2010, from http://www.thecochranelibrary.com

World Health Organization (WHO), 2002, WHO programme to Map Best Reproductive Health Practices - WHO Antenatal Care Randomized Trial: Manual for Implementation of the New Model, World Health Organisation, Geneva.

Zulfiqar, A., Bhutta, G., Darmstadt, L.G. \& Lawn, J.E., 2010, Saving the Children: The global picture and evidence-based solutions, An executive Summary for the BMC Pregnancy and Childbirth Supplement, C2 Digital, Cape Town. 